\title{
Trabalho, performance e os fatores de ansiedade do trabalhador
}

\author{
Work, performance and worker anxiety factors
}

\section{Thalita Lacerda Nobre}

Resumo: Esta pesquisa tem por objetivo discutir os principais fatores presentes na organização do trabalho atual que podem contribuir para o surgimento da ansiedade no trabalhador. Uma pesquisa nesta direção faz-se necessária para a discussão, no âmbito da Psicologia, sobre os impactos na saúde mental do trabalhador. A metodologia utilizada é a de cunho exploratório baseada em revisão de literatura, de autores e artigos atuais sobre o tema. Como resultados, encontra-se a noção de que a ansiedade é ocasionada pelo excesso de exigência que o indivíduo coloca sobre si a partir da exigência competitiva do meio de trabalho. Essas exigências estão ligadas ao discurso individual e social. Como estratégias possíveis, propõe-se como desafio ao profissional psicólogo, repensar em conjunto com as empresas o modo como o trabalho pode ser realizado a fim de manter-se desafiador e, ao mesmo tempo, respeitar o desejo e os limites da performance possível aos indivíduos, deixando de tornar-se fonte extrema de ansiedade.

Palavras-chave: Psicologia; Ansiedade; Trabalho.

\begin{abstract}
This research aims to discuss the main factors present in the organization of current work that can contribute to the emergence of anxiety in workers. Research in this direction is necessary for the discussion, in the scope of psychology, about the impacts on the mental health of the worker. The methodology used is that of an exploratory nature based on a literature review of authors and current articles on the subject. As a result, there is the notion that anxiety is caused by the excess of demands that the individual places on himself from the competitive demand of the work environment. These demands are linked to individual and social discourse. As possible strategies, it is proposed as a challenge to the professional psychologist, to rethink together with the companies how the work can be carried out in order to remain challenging and, at the same time, respect the desire and the limits of performance possible to individuals, failing to become an extreme source of anxiety.
\end{abstract}

Keywords: Psychology; Anxiety; Work.

\footnotetext{
1 Doutora em Psicologia pela PUC-SP. Psicóloga. Professora do Programa de Pós Graduação em Psicologia, Desenvolvimento e Políticas Públicas da Universidade Católica de Santos - UNISANTOS. E-mail: thalita.nobre@unisantos.br
} 


\section{Introdução}

Esta pesquisa é norteada pelo seguinte problema: que fatores da organização do trabalho contemporâneo podem contribuir para o surgimento da ansiedade no trabalhador?

A fim de investigar tal questão, constrói-se como objetivo o de analisar os fatores que podem levar à ansiedade do indivíduo trabalhador. Assim, a partir desse trabalho poderemos discutir a respeito da organização do trabalho na atualidade, levando em consideração os aspectos sociais que permeiam a vida contemporânea. É possível compreender que nas sociedades industrializadas, principalmente nos centros urbanos, tem-se um trabalho com alta competitividade, dinamismo e exigências constantes. A excelência está na ordem do dia. Diante dessa constatação, levanta-se a hipótese inicial de que a exigência de alta performance, característica da atual organização do trabalho, leva a alta competitividade.

Neste sentido, ao invés de levar muitos trabalhadores ao sentimento de desafio e busca por melhorar a qualidade do que fazem, entende-se que poderia gerar o contrário, fazendo muitos deles adoecer pelo excesso de ansiedade despertada por não corresponder às demandas. 0 trabalhador, a fim de cumprir com as exigências a que é exposto, pode sofrer intensa ansiedade. Neste sentido, é interessante compreender sobre os aspectos que influenciam diretamente 0 indivíduo que está inserido neste mercado, nesta forma de organização de atividades laborais que trazem exigências cada vez mais intensas de conhecimento mais amplo e, ao mesmo tempo, aprofundamento.

Para realizar tal estudo, parte-se das concepções de Dejours que desde o final da década de 70 do século XX iniciou seus estudos sobre a atividade laboral em correlação com os aspectos que levariam ao sofrimento e ansiedade, o que pode ser observado na obra"A loucura do trabalho". Seus estudos iniciados a partir da compreensão psicanalítica de representação psíquica do trabalho para o sujeito foi ampliado para a investigação acerca dos grupos e do discurso social na construção da subjetividade do trabalhador.

Mais adiante, na famosa obra"A Psicodinâmica do trabalho" postula que tal atividade é fonte de sofrimento, mas também, de prazer para o indivíduo, já que é por meio desta ação que pode ser encontrada a fonte da integração com a sociedade, bem como o sentimento de pertencimento, de influência, de participação e identidade ao grupo a que faz parte. Dejours se debruça sobre a teorização acerca do sofrimento psíquico e as formas de enfrentamento utilizadas pelos sujeitos para a adaptação ao trabalho e transformação da tarefa em fonte de prazer possível.

Por isso, acredita-se que seja importante considerar os aspectos intrínsecos e extrínsecos do trabalho, já que o indivíduo é produto da sociedade e a seu funcionamento deve, na medida do possível se adaptar ao mesmo tempo em que se configura como agente de mudança uma vez que se insere na cadeia produtiva com a importante função de transformar a matéria bruta em produto útil ao meio.

Observa-se, a partir dos levantamentos sobre o assunto que conforme as sociedades industrializadas vão se tornando mais dependentes da tecnologia e, por isso, compondo um trabalho cada vez mais rápido e transformador, essa exigência chegaria também ao indivíduo. Dito em outras palavras, se no início da organização do trabalho industrializado, os pensamentos tayloristas organizavam a relação homem-máquina na busca de o homem tornar-se produtivo com um trabalho mais simples e repetitivo, na atualidade, pode-se pensar sobre essa nova relação com o homem já incorporado à rapidez das máquinas, buscando a excelente performance. Eisso pode ser pensado como fonte de ansiedade e frustração, caso não seja alcançado.

Assim, esta pesquisa, que pode ser considerada de cunho exploratório e baseada em revisão de literatura, tem o intuito de ampliar a discussão sem a pretensão de esgotar o tópico, mas sim proporcionar reflexão a partir da contribuição de diversos autores sobre a temática, como um modo de diálogo, a fim de que sejam levantadas questões e clareamentos sobre 0 assunto.

\section{Panorama geral sobre a relação homem-trabalho}

Conforme Spector (2012, p. 3) escreve: "no mundo industrializado, a maioria das pessoas entra em contato direto ou indireto com organizações todos os dias". Isto quer dizer que a organização do trabalho faz parte da vida tanto do consumidor quanto do trabalhador.

Sendo assim, pode-se pensar na importância de contextualizar o mundo do trabalho à sociedade que vivemos. 0 trabalho pode ser compreendido como veículo de representação social, já que confere identidade para o sujeito e 0 insere no grupo que sente fazer parte. Acerca da atividade da representação social, Alves-Mazzotti (2008, p. 23) cita a partir do pensamento de Moscovici que não tem o caráter de reprodução passiva de um certo objeto, mas sim, "[...] de certa forma, o reconstrói e, a o fazê-lo, se constitui como sujeito, pois, ao apreendê-lo de uma dada maneira, ele próprio se situa no universo social e material."Isso significa que o indivíduo tem função reconstrutora dos objetos que compõem o mundo social. Todos são seres sociais e contribuem para 0 caminhar da sociedade.

A forma como 0 trabalho se organiza também diz respeito sobre 0 percurso realizado pelos indivíduos que compõem a sociedade, por isso, a importância da contextualização com a cultura e período histórico para a compreensão de cada um. Cada época histórica apresenta-se com um mal estar intrínseco é decorrente das formas de adaptação do indivíduo e da coletividade.

Hitt; Miller e Colella entendem que as empresas são formadas por pessoas e, portanto, tem seu modus operandi construído a partir da forma como isso se organiza. Para os autores:

Uma organização pode apresentar produtos e serviços de qualidade excepcionalmente elevada, um excelente nível de prestação de serviços ao consumidor, a melhor estrutura de custos da classe ou alguma outra vantagem, mas todos eles são produtos das competências das pessoas que fazem parte da organização (Hitt; Miller \& Colella, 2013, p. 11).

Daí a importância da atenção à saúde, passando pelos aspectos intrínsecos e extrínsecos que se relacionam ao trabalho a fim de contextualizar sobre que indivíduo é esse que se insere nas condições de produção que buscamos compreender.

A fim de ampliar a discussão, Dejours, em "A psicodinâmica do trabalho" (2007), propõe que a relação do homem com o trabalho é permeada por três fatores a serem considerados: 0 primeiro se refere ao fato do organismo do indivíduo não ser um "motor humano", ou seja, não é uma máquina que responde igualmente a estímulos, mas sim que possui um mundo interno que 
influencia na percepção do mundo externo. 0 segundo diz respeito à questão de que a relação do indivíduo com o trabalho pode se estabelecer à medida em que se considera que todos possuem uma história pessoal que contém aspirações e desejos próprios, o que "confere a cada indivíduo características únicas e pessoais" (Dejours, 2007, p. 24). 0 terceiro fator está relacionado às preferências do sujeito que se interliga com sua estrutura de personalidade, ou seja, o trabalho é algo que faz parte dos interesses que o indivíduo carrega consigo desde a infância, ao construir suas competências, que podem ou não se tornar habilidades.

A partir do entendimento sobre as questões que compõem a relação homem-trabalho, Dejours (2007) explicita que o modo como é percebida a atividade de trabalho pode ser relacionado ao fato de ser uma fonte de prazer ou uma terrível fonte de ansiedade. Este viés encontra-se inteiramente interligado ao sentido da função para o sujeito e à forma como se organizam as atividades para atender ou não as demandas psicológicas de cada um.

0 trabalho fatigante ou equilibrante, ou seja, que exija carga psíquica negativa ou positiva depende do envolvimento com os aspectos relativos à percepção do sujeito e ao mundo exterior. É a partir da carga psíquica que se deposita no trabalho que se originam as doenças mentais e a ansiedade.

Em "A loucura do trabalho" (1992, p. 75), Dejours aponta que as relações de trabalho, isto é, "todos os laços humanos criados pela organização do trabaIho..." são fatores que se superpõe às outras fontes de ansiedade, isso porque tais relações compreendem uma constante avaliação de rendimento do sujeito.

Nesse sentido, Dejours (1992, p. 77) elenca a possibilidade de ansiedade a partir de três formas possíveis, de acordo com o autor, uma delas é a"ansiedade relativa à degradação do funcionamento mental e do equilíbrio psicoafetivo", sendo essa resultante da desorganização das relações afetivas espontâneas entre os colegas de trabalho com a inclusão de sentimentos que envenenam as relações como violência e agressividade, ainda que veladas e características de um trabalho desorganizado. Isso gera tensão e ansiedade, o que pode levar 0 indivíduo a buscar recursos de fuga como o consumo de bebidas al coólicas ou uso de psicotrópicos, a agressão vivida pode ter repercussão de uma agressão interna, buscada pelo sujeito pelo uso de substâncias que prejudicam seu organismo e 0 convivio social. A desorganização do trabalho pode levar ainda, conforme Dejours postula, a estratégia defensiva da paralisação da criatividade e imaginação do sujeito e, em alguma medida, à despersonalização.

Um segundo modo de ansiedade decorrente das relações humanas no trabalho é denominado pelo autor de "ansiedade relativa à degradação do organismo" (1992, p. 78), relacionada ao risco sobre a integridade física, seja por conta de acidentes, desenvolvimento de doenças ou somatizações. Dejours define ainda que" (...) nas condições de trabalho é o corpo que recebe o impacto, enquanto que na organização do trabalho o alvo é o funcionamento mental" (1992, p. 78). E nesse sentido, compreende-se que o sofrimento decorrente dos impactos físicos se articula com o sofrimento mental, uma vez que corpo e mente sofrem exigências por adaptação seja no sentido de suportar a dor seja no de representar o sofrimento vivido pelo corpo.

Um terceiro modo de ansiedade postulada por Dejours é nomeada como "ansiedade gerada pela'disciplina da fome"' (1992, p. 78), é a forma menos abordada por autores sobre o tema é menos considerada também no meio organizacional, pois trata-se de um modo de sofrimento mental relacionado a condições fundamentais ao sujeito: a sobrevivência. Assim, essa forma de ansiedade está relacionada ao perigo da morte e muitos trabalhadores se expõem a determinadas condições porque precisam se custear e a família. Esse tipo de ansiedade pode ser devastadora porque coloca o indivíduo em uma condição de difícil possibilidade de movimentação.

É possível pensar também que esses três modos de ansiedade estão presentes durante todos os momentos históricos e culturais em que os indivíduos se encontram inseridos, porém, durante a pandemia do novo coronavírus, iniciada no ano de 2020 é possível conjecturar que tenha se potencializado.

Antes de ampliarmos a discussão acerca da especificidade da pandemia, faz-se importante compreendermos de que modo a ansiedade pode se instalar no sujeito devido às exigências do trabalho e o modo como 0 trabalho se organiza na atualidade.

Isso porque, como Flach et al (2009) comentam, o mundo do trabalho pós anos 2000, vem acumulando conquistas e retrocessos, já que se pode observar uma tendência em sua forma de organização ligada à possibilidade maior de participação dos funcionários, uma tendência à melhoria nas condições de vida e trabalho nas cidades, o aumento na preocupação com o risco de acidentes, uma tendência a valorização do pensamento, da criatividade e capacidade de tomar decisões, maior desgaste físico, entre outras características que compõem a diferença no mundo laboral da contemporaneidade. Segundo os autores acima citados, em concordância com Dejours (2007), 0 modo de organização da atividade e a exigência que ela representa permitirá configurar um modo de sofrimento para o sujeito.

\section{A organização do trabalho na sociedade atual}

Marx (1867/2008), em "0 capital" postula que o que confere valor à mercadoria é o trabalho despendido nela, essa seria a lei essencial do mercado, com a conferência em números (dinheiro) à força do trabalhador gasta para a transformação do produto pronto.

Neste sentido, a regra básica do capitalismo reside em uma organização da atividade laboral medida em números em que o trabalhador vende sua força física para o empregador, que compra e a utiliza para gerar produtos para a sociedade consumi-Ios. Os trabalhadores, com o dinheiro recebido pela troca que realizaram, compram outros produtos e movimentam a economia financeira. Esta é a forma simples de compreender o trabalho e, segundo Marx (1867/2008, p. 55) “[...] o trabalho simples, médio, varia segundo países e as épocas, porém sempre se acha determinado em uma dada sociedade, isto é, em cada sociedade."Assim, o valor pode ser atribuído de acordo com a cultura particular da sociedade em que o sujeito se encontra.

As sociedades mais industrializadas possuem uma organização do trabalho onde já se entende que a única forma de inserção do indivíduo como participante é por meio do oferecimento de sua força de trabalho e retorno financeiro deste. Martins e Pinheiro (2006, p. 80), citam ainda que, a medida em que a forma de organização capitalista se amplia, menos se valoriza o tempo do trabalhador, nas palavras dos autores: "[...] em face de uma aceleração crescente do desenvolvimento industrial, não deixa muito tempo livre para o trabalhador, durante a jornada da semana, do ano, da vida inteira."

Assim, é possível pensar a respeito do conceito de menos valia da força de trabalho proposta pelo próprio Marx, onde o capital, como objeto mais importante, desqualificaria o esforço do sujeito, ficando ele, cada vez mais escravo e tendo que oferecer cada vez mais de si para receber um retorno financeiro e de reconhecimento social. 
Pode-se pensar que a medida em que o trabalho tem se organizado com maior dependência da tecnologia, novas exigências vão surgindo para 0 trabalhador. Sendo assim, no contexto atual em que a informação se apresenta fluida e exige rapidez, também se exige uma grande transformação no modo de organização do trabalho e na forma como os recursos fluem.

Segundo Carlotto e Camara (2010, p. 309), nesse modelo de organização do trabalho: "as atenções do mundo global e neoliberal direcionam-se para a importância e a necessidade da informação, sendo pertinentes questões acerca de sua produção, uso, armazenamento e recuperação." Isso significa que a informação passa a ganhar um status no meio de produção, um valor de poder.

Carlotto e Camara (2010, p. 310) complementam ainda que, com 0 advento e difusão da comunicação, o mercado de trabalho tem se organizado de modo a exigir um perfil distinto de trabalhador, com as seguintes competências: "[...] deve saber lidar com conceitos, processar e interpretar dados, reconhecer modelos e entender o processo produtivo como um todo [...]". Dessa forma, o conhecimento técnico que leva o sujeito à vantagem competitiva seria aquele relacionado ao conhecimento amplo do processo. Haveria uma exigência de conhecimento aprofundado, porém com a característica de um pensamento a respeito das situações como um todo, o que diferencia do modelo de produção mecanicista do século XX, em que o trabalhador poderia se estabelecer como "peça da engrenagem", oferecendo sua mão de obra parcial para a produção do todo.

A exigência de perfil generalista e flexível às mudanças, com foco na excelência durante todo o tempo, da mesma forma que traz responsabilidade ao sujeito e propicia o pensar de modo distinto, estimulando a criatividade, também pode levar a um trabalho imprevisível, "[... nas quais o trabalhador tem que fazer escolhas e opções todo o tempo, ampliando-se as operações mentais e cognitivas envolvidas nas atividades." (Colenci \& Berti, 2012, p. 159). Por isso e outras questões pode-se pensar na ansiedade como principal fator denunciante de uma organização do trabalho que possa trazer sofrimento, uma carga negativa em detrimento da carga positiva, impedindo a satisfação do indivíduo.

\section{O sofrimento e a ansiedade no trabalho}

Conforme explicitado nos itens anteriores, o modo como o trabalho tem se organizado para satisfazer as exigências da realidade atual pode levar a condições muito particulares de sofrimento. Se por um lado, a rapidez de acesso à informação e a tendência ao autogerenciamento da vida laboral podem trazer benefícios ao sujeito produtivo e dinâmico, por outro, "[...] podem produzir problemas humanos e sociais que têm sido objeto de profundo debate devido às consequências para a saúde mental do trabalhador" (Carlotto \& (amara, 2010, p. 310).

A fim de possibilitar discussão acerca do assunto, passaremos a pensar a respeito dos impactos para o sujeito que se insere no movimento que pode trazer sofrimento. Assim, com o intuito de alertar sobre as fontes de sofrimento, Freud, em "0 mal estar na civilização" (1930/1996) escreve que a busca pela felicidade dos indivíduos pode ser restringida por fatores intrínsecos. Ao passo que, a infelicidade, como situação mais fácil de se experimentar pode ter sua causa oriunda de três possíveis direções, sejam eles:
[...] de nosso próprio corpo, condenado à decadência e à dissolução, e que nem mesmo pode dispensar o sofrimento e a ansiedade como sinais de advertência; do mundo externo, que pode voltar-se contra nós com forças de destruição esmagadoras e impiedosas; e, finalmente, de nossos relacionamentos com os outros homens. 0 sofrimento que provém dessa última fonte talvez nos seja mais penoso do que qualquer outro. Tendemos a encará-Io como uma espécie de acréscimo gratuito, embora ele não possa ser menos fatidicamente inevitável do que o sofrimento oriundo de outras fontes (Freud, 1926/1996, p. 84-5).

Isso significa dizer que, as relações que se estabelece com as pessoas pode tornar-se uma grande fonte de sofrimento para o sujeito. E, nesse sentido, pode-se pensar no possível empobrecimento da vida mental do indivíduo que pode se defrontar com conflitos decorrentes dessas relações, especificamente no trabalho. A atividade laboral tende a fazer-se presente em grande parte dos anos de vida das pessoas bem como em grande parte das horas diárias de dedicação das mesmas.

A fim de pensar sobre o sofrimento advindo das fontes externas, faz-se importante pensar a respeito da percepção do indivíduo, que "escolhe", ainda que inconscientemente, o sofrimento e seu nível, na relação com o outro. Por isso, éimportante ressaltar que a ansiedade, de acordo com Freud (1926/1996, p. 160): "[...] tem inegável relação com a expectativa: é ansiedade por algo." Por isso, a ansiedade pode ser decorrente da espera por algo que o remeta ao desamparo e que, em seu psiquismo, pode trazer sentimento de desprazer.

Freud (1926/1996, p. 161) complementa com exemplos, expondo que o que ocorre é o seguinte:

[...]'estou esperando que uma situação de desamparo sobrevenha' ou 'a presente situação me faz lembrar uma das experiências traumáticas que tive antes. Portanto, preverei o trauma e me comportarei como se ele já tivesse chegado, enquanto ainda houver tempo para pô-lo de lado.

E, nesse sentido, o indivíduo buscará se defender previamente do que pode ter detectado que traria sofrimento e desamparo.

Sendo assim, considerando que o sofrimento, em grande parte das vezes, vem de fora e é resultado da relação interpessoal e que a ansiedade é decorrente da detecção prévia do sentimento de desamparo que se buscará evitar, é possível pensar, também a partir das proposições de Dejours descritas no início desse artigo que pode haver atitudes defensivas do trabalhador para evitar sofrer e ser esquecido por todos os que o rodeiam e pelo mercado produtivo.

Martins e Pinheiro (2006) ampliam este raciocínio exposto anteriormente comentando que o sofrimento pode iniciar a partir das expectativas que 0 indivíduo construiu sobre seu trabalho e adequação à cultura. Quando este adentra a uma organização, tem planos de que serão supridas suas necessidades que podem ser correspondidos à medida em que sente encaixar-se bem com o que é oferecido pela empresa. Ao passo que, quando isso não acontece, há um desencaixe entre indivíduo e empresa, o que pode levar a mesma a 
cobrar resultados do trabalhador. Sendo assim, é possível que o trabalhador, "por sua vez, acredite nesta 'verdade' e passa a desenvolver uma relação de sofrimento consigo mesmo e com a organização" (Martins \& Pinheiro, 2006, p. 81). 0 contrário também pode ser observável, o sujeito pode criar expectativas muito grandes em relação à empresa, que para aquele tipo de cultura não conseguirá corresponder, surgindo uma relação de hostilidade com a mesma.

Essa relação conturbada pode levar a ansiedade, exigir que o indivíduo desenvolva recursos para fugir da iminência (percebida por ele) de uma situação de desamparo.

De acordo com Motta (2012, p. 22), há uma tendência atual à manutenção da performance. Para o autor, o modo como o trabalho tem se estruturado leva"muitos gestores e funcionários [...] ficar fascinados pelas possibilidades materiais e de poder e prestígio e, motivados por metas antes impensadas, se superam na busca da sobrevivência."A expectativa de superação de seus limites compreende uma linha tênue com o fracasso e com o risco da insegurança, da possibilidade de perder o lugar para outro com melhor performance.

Neste sentido, os desafios passariam de uma condição "saudável" que levaria 0 sujeito à buscar superação e competitividade que impulsionam para a construção e a criatividade para a realização de tarefas a fim de evitar o desamparo, o não reconhecimento.

A ansiedade constante pode proporcionar alterações fisiológicas e psicológicas que levam à consequências nefastas à saúde física e mental do indivíduo. Tais consequências podem variar de acordo com o gênero, tipo de trabalho e características individuais. (Medeiros Neto et al, 2012).

Como exemplo, Motta (2012) analisa as exigências vividas pela função gerencial e discute que em funções com mais alto nível de prerrogativas, há também maiores níveis de exigência diante da responsabilidade que tem por seus funcionários. Neste sentido, o funcionário pode sentir-se dividido entre o exigido pela empresa, pelos funcionários (seus liderados) e pelo cliente, levando-0 a estar sempre em alerta. Por isso, 0 autor aponta que:

[...] a ansiedade e sua transformação em sintomas mais agudos dependem menos do problema e mais da forma de a pessoa lidar com a situação de risco. Daí a necessidade de se estudarem formas mais adequadas da percepção de risco e mais positivas de se aproximar da realidade (Motta, 2012, p. 25).

Esse destaque do autor permite compreender sobre a humanidade do trabalhador e sobre os riscos de manter-se o tempo todo em prol da performance, além da importância dos psicólogos auxiliarem na transformação deste modo de enxergar o trabalho, com levantamento de formas mais adequadas às possibilidades humanas de correspondência às exigências.

Motta levanta algumas características de ansiedade que podem ser observadas no sujeito que vive alta exigência de performance, são elas: "sensibilidade excessiva, maximização de problemas e concentração nos fatores negativos, Dispersão mental e transferência da decisão, comunicações irrealistas e incremento da conversa consigo próprio"(Motta, 2012, p. 25-26). Tais aspectos levantados pelo autor estão relacionados a uma espécie de dissociação do sujeito com o outro e com seu trabalho. Poderia ser explicado pela carga excessiva de exigência interna que afeta pesadamente na percepção da realidade e das características realísticas das pessoas que o cercam.
Tais aspectos, quando vividos, levam ao intenso sofrimento e isolamento, ao perceber isso, o sujeito sente-se cobrado mais e mais (internamente e externamente), o que o leva a tomar atitudes defensivas a fim de garantir sua mínima organização mental. Por essa razão, comportamentos de descargas agressivas e relacionados ao assédio moral podem tornar-se realidade para tais indivíduos.

Alguns autores têm se debruçado à compreensão da ansiedade decorrente das formas atuais de organização do trabalho, como exemplo de referência pode-se destacar os estudos da profa. Dra. Ana Magnolia Mendes com a organização da obra "Psicodinâmica do trabalho: teoria, método e pesquisas" (2007). Nessa obra há a descrição da construção do "Inventário do Trabalho e Riscos de adoecimento" (ITRA), que fora baseado na abordagem da psicodinâmica do trabalho, ainda que, conforme os autores afirmam que essa abordagem seja de natureza de preponderância qualitativa, os instrumentos psicométricos podem auxiliar na compreensão, de maneira sistemática, dos processos de subjetivação decorrentes da organização do trabalho.

Na organização desse instrumento, Mendes e Ferreira (2007, p. 114) afirmam que" ITRA tem como objetivo mensurar distintas e interdependentes modalidades de representações dos respondentes, relativas ao mundo do trabalho". E, nesse sentido, os autores apresentam diversas pesquisas com populações diferentes, de distintas atividades laborais em que se pode observar e refletir acerca das estratégias defensivas criadas de acordo com a necessidade de resistência às situações adversas. Esses estudos rendem frutos que se ampliam para outros relacionados à psicopatologia do trabalho e, mais especificamente, à questão da ansiedade.

Acerca da ansiedade, há estudos atuais que abordam os principais aspectos em diversas realidades, como o estudo de Ribeiro et al (2019) que traz uma revisão integrativa de publicações referentes ao assunto no período de uma década, de 2006 a 2016, consultando pesquisas realizadas em países europeus e no Brasil. Tal estudo observa que a realidade brasileira ainda se apresenta como deficitária no que diz respeito à atenção aos transtornos ansiosos decorrentes da atividade laboral, apesar de corroborar os estudos de outros países que apresentam evidências de ....alta prevalência dos transtornos ansiosos como causa dos afastamentos do trabalho e da alta demanda de custos com auxílio-doença" (2019, p. 7). Isso significa que, independente da realidade cultural, a organização do trabalho necessita ser pensada e refletida a fim de realizar intervenções necessárias para o bem estar.

Os autores discutem ainda que o afastamento do trabalho tende a gerar efeitos nefastos na vida laboral, afetiva e familiar do indivíduo, uma vez que impõem limitações à vida cotidiana desse sujeito. Nesse sentido, ressalta-se a importância do conhecimento do perfil do trabalhador e das estratégias de resistência utilizadas, "...uma vez que possibilita o diagnóstico situacional, contribui para o reconhecimento dos fatores de risco e auxilia nas estratégias de intervenção direcionadas à melhoria das condições de trabalho, na qualidade de vida e na redução do afastamento laboral" (Ribeiro et al, 2019, p. 7).

Em consonância com o estudo de Ribeiro et al, uma vez observadas as características defensivas no trabalhador, Carlotto e Camara (2010) compreendem também que há necessidade de pensar em "[...] ações de prevenção, a fim de evitar riscos e efeitos negativos para 0 trabalhador $e$, em consequência, para a organização" (Carlotto \& Camara, 2010, p. 312). Ou seja, tais autores, como diversos outros, levantam sobre a importância de repensar as práticas a partir do diálogo com a empresa e o sujeito que nela 
se insere, uma vez que a organização do trabalho compreende a relação entre empregador e empregado.

Bergamini (2015) propõe uma visão ampla entre o social e as formas de ajustamento do trabalho ao contexto, por isso se encaixa em um novo ramo de especialização na compreensão e estudo do comportamento humano: a psicopatologia do comportamento organizacional. Nessa modalidade, há a perspectiva de que o diálogo entre empresa e trabalhador é mais profícuo quando os especialistas auxiliam as pessoas, isto é:" [...] à medida que facilitem a elas se conhecerem melhor. Isso neutraliza as sensações desconfortáveis a respeito delas mesmas, como, por exemplo, sentimentos de autoestima rebaixados, falta de confiança ao sentirem que falharam" (Bergamini, 2015, p. 5).

As pessoas, conforme se conhecem mais, se empoderam e criam condições para a crítica sobre si mesmas e sobre o trabalho que realizam. As empresas, por sua vez, passam a se relacionar com pessoas que adquirem capacidade de estabelecer relações mais saudáveis com o trabalho e com as pessoas do seu meio, permitindo também um trabalho mais desafiador e menos baseado em estratégias defensivas.

\section{Discussão}

Os resultados obtidos com a pesquisa relacionam-se com a compreensão de diversos autores sobre o tema da organização do trabalho e a consequente ansiedade que pode surgir no trabalhador. Durante a pesquisa, percebeu-se que al guns autores como Martins e Pinheiro (2006) possuem uma visão destinada às questões da opressão do empregador ao empregado. Observou-se que tal abordagem pode ser interessante na ampliação do pensamento de que haveria a tendência ainda ao oferecimento ao trabalhador de um papel passivo, sem condições de expressão de sua criatividade ou de voz que possibilitasse diálogo entre as partes.

Também foi obtido, por outro lado, alguns autores como Dejours, Bergamini, Hitt; Miller e Colella, Mendes, Ribeiro, entre outros que propõem que as empresas têm uma grande função de atenção ao modo como 0 trabalho se organiza e a consequente formação de atitudes defensivas por parte do trabalhador e dela própria, o que levaria a um trabalho doentio e com grandes dificuldades de modificações necessárias para obter-se o melhor de ambas as partes.

Neste sentido, este trabalho tem a função de discutir que o diálogo entre empresa e empregador pode ser possível e mediado por ideias propostas pelos psicólogos. Para isso, acredita-se ser importante atentar-se aos aspectos sociais do contexto atual da cultura bem como à incorporação da tecnologia da informação e comunicação no mundo do trabalho. Assim, passaria por essa discussão, a modulação da cultura organizacional e a importância de relacioná-la ao clima interpessoal.

\section{Considerações finais}

Esta pesquisa teve 0 intuito de discutir sobre as questões principais que permeiam o mundo do trabalho na atualidade. As formas possíveis do indivíduo conseguir seu sustento estão relacionadas à forma como se organiza a atividade do trabalho. A psicologia social compreende o indivíduo como produto e produtor do meio em que vive e também entende que há uma interação constante entre trabalhador e empresa que se modifica à medida que se alteram os discursos sociais e há necessidade de adaptação a novas formas de execução do trabalho.

Neste sentido, a partir da observação de queixas dos trabalhadores e empregadores e da construção deste trabalho de pesquisa, pode-se ampliar a hipótese de que a forma como se organiza o trabalho na atualidade, em sociedades industrializadas, com um nível de exigência altíssimo em termos de performance, pode levar a estratégias defensivas do ponto de vista empresarial e, à ansiedade do trabalhador. Além da competitividade, outros fatores como 0 sentido do trabalho para o indivíduo, a forma como sente ser tratado por seus superiores e colegas, a cultura organizacional, o uso extensivo da tecnologia, entre outros podem ser entendidos como desencadeantes de ansiedade.

Entende-se que a ansiedade do indivíduo é decorrente, fundamentalmente, do medo do perigo real de não corresponder ao que acredita que o mercado gostaria que oferecesse. Desta forma, se por um lado, a competitividade pode ser entendida como boa a medida que leva o sujeito a buscar novos desafios e a usar a criatividade, por outro lado, isso pode estar sendo levado a níveis astronômicos e sobre-humanos, o que alimentaria um sentimento de ansiedade constante levando ao stress e descargas agressivas defensivas que atrapalham a boa convivência e o direcionamento da energia em atividades produtivas.

Ao final do estudo, também se conclui que há a importância de 0 profissional Psicólogo pensar e se envolver em um importante diálogo entre organização e trabalhador, investindo em uma visão ampla da sociedade e no autoconhecimento por parte do trabalhador: de seus desejos e anseios, a fim de que haja empoderamento diante de seu papel social e de contribuinte da sociedade.

\section{Referências}

Alves-Mazzotti, A.J. (2008). Representações sociais: aspectos teóricos e aplicações à educação. Revista Múltiplas Leituras, 1(1), 18-43.

Bergamini, C.W. (2015). Psicologia aplicada à administração de empresas: Psicologia do comportamento organizacional. 5a. Ed. São Paulo: Atlas.

Carlotto, M. S. \& Câmara, S. G. (2010). 0 tecnoestresse em trabalhadores que atuam com tecnologia de informação e comunicação. Psicologia: Ciência eProfissão, 30(2), 308-317

Colenci, B. \& Berti, H.W. (2012). Formação profissional e inserção no mercado de trabalho: percepções de egressos de graduação em enfermagem. Revista da Escola de Enfermagem da USP, 46(1), 158-66.

Dejours, C. (1992). A loucura do trabalho: estudo de psicopatologia do trabalho. 5a.ed. São Paulo: Cortez - Oboré.

Dejours, C. (2007). Psicodinâmica do trabalho. 1a. Ed. 9 reimpr. São Paulo: Atlas. Flach, L. (2009). Sofrimento psíquico no trabalho contemporâneo: analisando uma revista de negócios. Revista Psicologia \& Sociedade, 21(2), 193-202.

Freud, S. (1996) Inibições, sintomas e ansiedade. ESB, vol. XX, Rio de Janeiro: Imago. (Original publicado em 1926).

Freud, S(1996) O mal-estarna civilização. ESB, vol. XXI, Rio de Janeiro: Imago. (Original publicado em 1930).

Hitt, M.A.; Miller, C. \& Colella, A. (2013). Comportamento Organizacional. 3a. Ed. Rio de Janeiro: LTC.

Martins, J.C.0 \& Pinheiro, A.A.G. (2006). Sofrimento nas relações de trabalho. PSIC - Revista de Psicologia da Vetor Editora. 7(1), 79-85.

Marx, K. (2008). O capital - edição condensada. São Paulo: Edipro. 
Medeiros Neto, C.F. et al. (2012). Análise da percepção da fadiga, estresse e ansiedade em trabalhadores de uma indústria de calçados. Jornal Brasileiro de Psiquiatria. 61(3), 133-8.

Mendes, A. M.; Ferreira, M. C. \& Cruz, R. M. (2007). Inventário sobre Trabalho e Riscos de Adoecimento - ITRA: Instrumento auxiliar de diagnóstico de indicadores críticos no trabalho. In A. M. Mendes (Org.), Psicodinâmica do Trabalho: teoria, método e pesquisas (pp. 111-126). São Paulo: Casa do Psicólogo.

Motta, P.R. (2012). Ansiedade e medo na empresa: percepção de risco das decisões gerenciais. Revista Portuguesa e Brasileira de Gestão [on line], $11(2-3), 22-37$.

Ribeiro, H. K. P. et al. (2019). Transtornos de ansiedade como causa de afastamentos laborais. Revista Brasileira de Saúde Ocupacional, 44(1), 1-8.

Spector, P. (2012). Psicologia nas organizações. 4.ed. São Paulo: Saraiva. 